\title{
PANDEMIA E FRATERNIDADE, UM PARADOXO NECESSÁRIO: O FRUTO QUE PODEMOS COLHER
}

\author{
Fabiana Dantas Soares Alves da Mota ${ }^{1}$ \\ Zéu Palmeira Sobrinho ${ }^{2}$
}

DOI: https://doi.org/10.47306/978-65-88213-03-2.423-432

Sumário: 1 Introdução; 2 Pandemia: o paradoxo da experiência; 3 O paradoxo da esperança: qual fraternidade para qual futuro?; 4 Conclusão; Referências.

\section{Introdução}

O objeto do presente artigo é situar a pandemia em seu contexto político, bem como buscar conhecer as repercussões do aludido fenômeno nas searas sanitária, cotidiana, econômica e psicossocial e, por fim, compreender as possibilidades e as condições para uma transformação societal à luz da fraternidade.

A importância do tema não se limita apenas ao debate sobre as implicações que a humanidade poderá retirar do impacto da pandemia sobre as vidas das pessoas. O maior desafio da humanidade é se debruçar sobre as condições predatórias que historicamente engendraram as relações sociais, entre os homens e as relações destes para com a natureza, e dificultam a continuidade da espécie humana no planeta terra. Os estragos causados pelo vírus COVID-19 não seriam tão desastrosos se a humanidade não vivesse sob um modo de produção que continua a reduzir tudo à mercadoria e a transformar as relações entre pessoas numa relação entre coisas. É no contexto de tal transformação que, sob capitalismo, a humanidade e a natureza vêm sendo coisificadas como cobaias do mercado, segundo a estratégia de reprodução das relações de exploração baseadas no neoliberalismo.

$\mathrm{O}$ trabalho que ora se apresenta estrutura-se em dois eixos. $\mathrm{O}$ primeiro refere-se ao paradoxo da experiência. A palavra paradoxo aqui está posta com o sentido do que é imperceptível e que precisa vir à tona, para ser conhecido, debatido e transformado. Até o momento, por mais que a mídia mundial tenha escancarado ao mundo os estragos provocados

\footnotetext{
${ }^{1}$ Professora da UFRN, Advogada, Pós-graduada em Direito Público; Mestre em Direito Constitucional (UFRN); Membro do GESTO-UFRN (Grupo de pesquisas direitos sociais e contemporaneidade); Coordenadora do NETINUFRN (Núcleo de estudos sobre trabalho infantil); e-mail: fabianadsamota@gmail.com

2 Professor doutor da UFRN, Juiz do Trabalho da 21 Região, Gestor Regional do Programa de Combate ao Trabalho Infantil, Coordenador do GESTO (Grupo de pesquisas direitos sociais e contemporaneidade), Coordenador-Adjunto do NETIN-UFRN
} 
pela COVID-19, subsiste uma tendência de erosibilidade da memória, provavelmente em curtíssimo tempo, em relação ao sofrimento, as mortes, a dor e ao luto de muitos e as posturas de insensibilidade, arrogância e avareza de outros. Para que a humanidade não deixe que fatos históricos tão impactantes caiam no esquecimento, urge tematizá-los como condição de tirar implicações da experiência para um futuro transformador e fraterno.

O segundo eixo do trabalho, indo além da mera recordação sobre os sofrimentos causados pela pandemia, consiste na seguinte indagação: qual o elemento político nuclear capaz de definir se o futuro da humanidade caminhará para a barbárie ou para a civilização?

Tematizar a invisibilidade da experiência vivenciada pela humanidade desafia saber se a pandemia será capaz de provocar ou não o descortinamento da sociedade em relação ao capitalismo. O paradoxo continua em se saber se o véu, uma vez retirado, será suficiente ou não para sinalizar dois aspectos: primeiro, o modo como o capitalismo desumaniza as relações sociais e destrói as condições de reprodução da humanidade; e, segundo, a urgência de um resgate da fraternidade capaz de trazer sensibilidade, dialogicidade, conscientização e uma transformação humanescente.

\section{Pandemia: o paradoxo da experiência}

No final do ano de 2019 o mundo conheceu um vírus de capacidade mortal voraz, que em poucos meses tomou conta do mundo e contaminou boa parte da população do planeta. Em 11 de março de 2020 a Organização Mundial da Saúde - OMS declarou o estado de pandemia (BRANSWELL; JOSEPH, 2020). Até o dia 15 de junho, 7.973 .302 casos foram computados e 434.793 mortes contabilizadas (HOPKINS, 2020), com projeção de infecção de até $2 / 3$ da população mundial, além de mutação constante do vírus, como apontam as pesquisas mais recentes.

O vírus Covid-19 traz consigo consequências de ordem social, econômica, financeira e política, uma catástrofe cujas proporções não são vistas desde a Segunda Grande Guerra Mundial, que trouxe uma crise com a qual se tem que conviver até hoje, principalmente agravada nos países que já vinham adotando o receituário neoliberal e se submetendo à tirania do sistema financeiro.

Boaventura de Sousa Santos, isolado sob os efeitos das estratégias governamentais de enfrentamento da pandemia, escreveu "A Cruel Pedagogia do Vírus", ocasião em que lembra tratar-se de um agravamento da crise "permanente" já existente, cujo objeto é mesmo não ser resolvida, já que justifica cortes em políticas sociais e baixos salários, que, por sua vez, visam 
"legitimar a escandalosa concentração de riqueza e boicotar medidas eficazes para impedir a iminente catástrofe ecológica" (SANTOS, 2020, p. 5).

Na mesma obra, o autor relata a constatação de recuperação do meio ambiente durante do período de quarentena, ao tempo em que questiona a impossibilidade de convivência de ambos de modo saudável, como única alternativa. Ousa-se responder que não, precisa-se aprender e conviver de modo saudável, homem-meio ambiente, esta sim, é uma alternativa válida e eficaz, que satisfaz o mundo em todas as suas nuances (SANTOS, 2020).

Leonardo Boff já trabalha há bastante tempo a necessidade de cuidar, de ensinar a cuidar, de saber cuidar, do cuidado mútuo, da solidariedade (BOFF, 1999).

A par disso, ainda se há que lidar com as fake News, teorias da conspiração e desinformação, grande problema inclusive aqui no Brasil, gerando ao final uma polarização sem-fim, o que obrigou a OMS a agir a fim de promover desmistificação de muitas destas notícias, o que poderia ser evitado ao se atravessar esta pandemia com a ética e seriedade que a situação exige.

Ademais, é sabido que as desigualdades sociais se agravam e agravam ainda mais este período, a exemplo de favelas como as de São Paulo e Rio de Janeiro, onde há locais que sequer chega água encanada ou se tem meios para comprar sabão, para cumprir com o simples ato de lavar as mãos, recomendação básica de prevenção e contenção do vírus, ou mesmo a impossibilidade de isolamento, tendo em vista viver uma família inteira em um ou dois cômodos comuns, gerando a aglomeração não intencional, por absoluta falta de meios de realizar o isolamento.

Como não lembrar, dentro da atual conjuntura, da Pedagogia do Oprimido, da Pedagogia da Esperança, de Paulo Freire, ora estes são os "oprimidos aos esfarrapados do mundo e aos que neles se descobrem e, assim descobrindo-se, com eles sofrem, mas, sobretudo, com eles lutam" (FREIRE, 1987, p. 15).

Muito desde contexto nos remete ao Século XVII, por meio do capitalismo desenfreado reinante, o colonialismo e o patriarcalismo, cujas consequências dentre elas a concentração de riqueza, desigualdades sociais e a o própria destruição do meio ambiente (SANTOS, 2020), que desencadeiam ainda a violência nos lares, assolando principalmente crianças e mulheres, provocando um aumento aterrorizante nos números de violência doméstica (SENADO FEDERAL, 2020) situação em que seres humanos, na sua superioridade patriarcal, agridem mulheres e crianças, violentado não só seu físico, mas também almas, de modo indelével, deixando evidentes a discriminação sexista nos índices de feminicídio (CÂMARA DOS DEPUTADOS, 2020). 
A quarentena, que poderia trazer a maior convivência intrafamiliar em muitos lares, em razão do próprio machismo, é permeada de estresse, já que numa grande parcela dos lares e para a maioria das mulheres há não a divisão de tarefas, mas sim a acumulação das laborais e institucionais, com os afazeres domésticos, além do maior tempo de cuidado dispensado aos filhos, também reclusos em tempo integral em casa, por força da pandemia, aumentando as discussões e a violência conjugais.

Santos traz a realidade pandêmica vivenciada por vários grupos sociais, a exemplo do citado acima, mulheres, os moradores das periferias mais carentes das cidades, favelas, etc, que por mais das vezes não têm acesso a simples água potável ou mesmo a eletricidade, o que ele bem caracteriza como pessoas que "habitam na cidade sem direito a cidade", sem poder cumprir cuidados comezinhos recomendados pelas autoridades sanitárias, como lavar as mãos, manter a distância de segurança, se sujeitam a um "hetero-isolamento" já imposto em suas vidas indefinidamente (SANTOS, 2020, p. 18), à proporção que já não se fazem circular em determinados ambientes, normalmente, tais como praias e shoppings.

Lembra o mesmo autor ainda dos internados em campos de refugiados e similares, que dependem de políticas humanitárias para sobreviverem; dos deficientes, pessoas que dependem de outras pessoas que terão que sair de seus próprios isolamentos para lhes dispensar cuidados básicos, inclusive higiênicos; dos presos, aglomerados em suas cadeias imundas, também sem poder receber visitas; dos idosos, grupo extremamente vulnerável, que precisa se valer do autoisolamento e, assim, da solidão; isso os mais abastados, pois os pobres, sem saída, hão que se sujeitar a convivência em um cômodo com os demais familiares, que por vezes precisam sair pra trabalhar e ganhar o pão, à vista da ausência de uma política pública que permita a subsistência, e, por consequência, retornam a seus lares violando a proteção de todos, durante este período pandêmico. Acrescente-se o indígena, que sofre ainda mais pela indiferença governamental evidente à sua especificidade.

Já que as desigualdades vieram à tona com mais intensidade neste período ora vivido pela população mundial, e com mais razão aqui no Brasil, país gigante em extensão e grandioso em população, dividindo pobres e ricos em quarentenas tão distintas, ambas de tristeza, mas uma apaziguada pelo gozo da garantia do salário no fim de mês, com ou sem labor, da mesa farta, internet banda larga, equipamentos de última geração, webcams, uma infinidade de lives, de uma certa economia com gastos extras, tais como combustível, passeios ao shopping e idas a restaurantes caros, outra de intranquilidade e incerteza com o dia de amanhã, com o alimento de amanhã, um lar, um lugar para morar amanhã, o emprego que posso não ter mais no dia 
seguinte, a água para higienizar as mãos e roupas que não se sabe se cairá amanhã das torneiras, a luz que pode ser cortada pela falta de pagamento, amanhã.

Enfim, são muitas incertezas que permeiam cabeças e lares de grande parte da população, onde tais quarentenas se constituem em pólos extremamente opostos, muitos ansiosos e depressivos por não ter o que fazer, mesmo tendo ao seu redor livros, computador, celular, tablets, webcams, Tv e internet banda larga, 5G, uma infinidade de artigos de luxo e boa comida; outros, entregando a boa comida, sem poder saborear, sem sequer saber se terá o suficiente para alimentar a família no outro dia, ansioso e por isso, deprimido também por isso, mas sem poder se dar uma quarentena em casa, segura, longe do vírus, tendo que enfrentá-lo todos os dias nas entregas das compras de mercado, dos restaurantes, das farmácias, entregando tudo de que não pode usufruir, na busca simplesmente por sobreviver a esta pandemia, sem sequer imaginar que outras estão a caminho, mais severas do que esta, mais invasivas, mais seletivas.

A disparidade é vista já a partir do tratamento dispensado pelas escolas às crianças, situação em que as que estudam em boas escolas particulares, estão tendo acompanhamento e aulas on-line, em computadores ou celulares ligados à internet, com capacidade para atender tal necessidade, enquanto os alunos de escola pública encontram-se sem aulas, sem perspectiva de retorno, sem um projeto ou política básica que lhes permita usufruir do básico numa sociedade civilizada, a educação. E, por fim, sem a empatia e sabedoria necessárias de autoridades governamentais, que insistem em manter exames nacionais de aprendizado e seleção para alçar o nível superior, em evidente disparidade de condições dos participantes, agravando as desigualdades já impostas pela seleção já imposta desde os anos iniciais educacionais, por meio do segmento de alunos da rede pública e particular, a exemplo do que ocorre no Brasil.

É impossível ver tudo isso e não se questionar sobre a sociedade em que vivemos e a distância entre aquela que queremos...é necessário chamar a baila a sabedoria de Freire ao invocar a "unidade na diversidade" (FREIRE, 1992, p. 78), e a do Papa Francisco ao afirmar que "sem uma visão de conjunto, não haverá futuro para ninguém" (FRANCISO, 2020, p. 55), insistindo para que estas minorias tomem ciência que estes grupos isolados da população se constituem, na verdade em maioria, uma maioria que está sofrendo os horrores de uma guerra contra um vírus invisível e pouco conhecido.

Francisco, coloca a realidade vivida em todo o mundo, com seus olhos de amor: "É o peso da pedra sepulcral que se impõe perante o futuro e que, com o seu realismo, ameaça enterrar toda a esperança. É o peso da angústia de pessoas vulneráveis e idosas que passam pela quarentena na solidão mais absoluta", trazendo a lume o fardo que cada um carrega: "é o peso 
das famílias que já não sabem como pôr na mesa um prato de comida, é o peso dos profissionais da saúde e da segurança, quando se sentem exaustos e sobrecarregados... este peso que parece ter a última palavra". (FRANCISCO, 2020, p. 44)

No mar de sentimentos, surgem ondas de medo, solidão, carência, saudade, e atores como fome, miséria, pobreza, desemprego, depressão e mortes, onde se faz necessário buscar algo maior que a solidariedade para sustentar uma confusão de tantos problemas ao mesmo tempo, essa turbulência coletiva: a fraternidade, a necessidade de pensar no outro, cuidar do outro, sentir como o outro. É dela que vamos nos valer na abordagem do próximo tópico.

\section{O paradoxo da esperança: qual fraternidade para qual futuro?}

A partir desta experiência pela qual o mundo passa neste momento, o Papa aduz que "Uma emergência como a da Covid-19 derrota-se antes de tudo com os anticorpos da solidariedade" (FRANCISCO, 2020, p. 50). Eis o nosso esperançar.

Necessário, portanto, se reconhecer como sujeito e protagonista da história, se inserir e construir o mundo, não somente adaptar-se a ele e a suas imposições, urge ser fio condutor e "motor da história". É preciso, diante do cenário pandêmico, ter esperança, ser esperança, esperar com esperança, a fim de construirmos uma sociedade melhor, pois reverberando Freire "não há mudança sem sonho, como não há sonho sem esperança” (FREIRE, 1992, p. 47).

O espetáculo é caótico, a necessidade de sonhar, de ter esperança e de promover mudança, um fato. Para tanto, é preciso empatia, sentir como o outro sente, agarrar-se a fraternidade, e seguir, entendendo que ninguém se salva sozinho e que há um vírus de maior potencial que devemos temer, o do egoísmo (FRANCISCO, 2020). Este sim, causa estragos ainda maiores do que os atuais.

Eis as palavras do Para Francisco quanto a situação vivida hoje: "Quão difícil é ficar em casa para quem mora em uma pequena casa precária ou para quem de fato não tem teto". Acrescenta: “Quão difícil é para os migrantes, as pessoas privadas de liberdade ou para aqueles que realizam um processo de cura para dependências" (FRANCISCO, 2020, p. 8). Consegue enxergar categorias que se pensa estarem em pé de igualde: "Penso nas pessoas, especialmente mulheres, que multiplicam o pão nos refeitórios comunitários, cozinhando com duas cebolas e um pacote de arroz um delicioso guisado para centenas de crianças" (FRANCISCO, 2020, p. 8). Enxerga além, ao afirmar: "penso nos doentes, penso nos idosos. [...] nos camponeses e os agricultores familiares, que continuam a trabalhar para produzir alimentos saudáveis, sem 
destruir a natureza, sem monopolizá-los ou especular com a necessidade do povo" (FRANCISCO, 2020, p. 9) e vê, certamente também, muitos indo embora sem se despedir...

Roga, no mesmo livro, “que pensemos no projeto de desenvolvimento humano integral que ansiamos, focado no protagonismo dos Povos em toda a sua diversidade e no acesso universal aos três T que vocês defendem: terra e comida, teto e trabalho". (FRANCISCO, 2020, p. 40-41).

A fim de se buscar concretizar e satisfazer necessidades mínimas dos seres humanos, direitos fundamentais tais como um lar, alimentos e um trabalho, e dentro desta pandemia, urge clamar por um princípio que se fundamentou nos ideais da Revolução Francesa, o princípio da fraternidade. A burguesia revolucionária lastreou sua ação política em três princípios, a saber: a igualdade, a liberdade e a fraternidade. Nenhuma das mencionadas premissas axiológicas foram concretizadas, mas dentre todas a mais desprezada foi a fraternidade.

De difícil conceituação, vai de concepções liberais, republicanas, cristãs e socialistas, sem olvidar, em qualquer delas, a necessidade de olhar o próximo, em pé de igualdade com si próprio. O conceito de fraternidade é complexo, analisado em dimensões, no qual se veem a dimensão comunitária, a afetiva e a prática. (AMAYA, 2016).

A dimensão comunitária pressupõe vínculo comum que permeia as relações fraternas, nas quais se compartilham vínculos, "En las relaciones fraternales, los individuos reconocen a los otros como iguales en virtud del valor compartido, e.g., la común humanidad, la condición de mujer, la pertenencia a un movimiento obrero, etcétera"33 (AMAYA, 2016, p. 30). Aqui, as responsabilidades, direitos e obrigações também são compartilhadas em razão do elo que os une.

A dimensão afetiva tem como características os sentimentos de amor, lealdade, confiança, empatia, entre outros; e, por fim, a dimensão prática, onde os vínculos se mostram desinteressados, dispostos a um compartilhamento inclusive de bens materiais, se necessário, altruísticos mesmo, de modo que o conceito de fraternidade pode estar imbuído de uma comunidade mais ou menos ampla, a depender dos comportamentos adotados, sendo realizada quando cada membro se reconhece igual e compartilha valores, são ligados por laços de afeto, e se dispõem a ajuda mútua. (AMAYA, 2016).

A fraternidade não é só lema, nem tampouco só princípio, sua força é muito maior e na realidade, vem de antes da própria Revolução de que foi lema, pois é conhecida desde a antiguidade, com um longo histórico, perpassando por laços familiares, dentre outros, tais quais

\footnotetext{
3 "Nas relações fraternas, os indivíduos reconhecem os outros como iguais em virtude do valor compartilhado, ex., a humanidade comum, a condição de mulher, a participação em um movimento trabalhista, etc." (tradução nossa)
} 
liames comerciais da era medieval e vínculos ético-políticos no período helenístico, fazendo-se presente, ainda, em textos constitucionais a partir de 1948, como o da Constituição francesa de 1948, em seu preâmbulo, bem assim em movimentos sociais e laborais da época, com a identificação de sua presença se esvaindo a partir da metade do século XIX. (AMAYA, 2016).

Há que se questionar os motivos pelos quais tal mitigação acontece, situação sobre a qual Amalia Amaya traduz tal estranhamento em algumas hipóteses, dentre as quais se destacam: a fraternidade não se coaduna com individualismo típico do liberalismo, muito ao contrário, se liga a objetivos comuns; o tipo de vínculo social exigido para que esta se estabeleça, dissonante da sociedade atual de grande escala; a liberdade e igualdade se utilizam de meios jurídicos e reformas políticas para sua efetivação, enquanto que ainda não se tem os mecanismos próprios para que a fraternidade se concretize; a incompatibilidade da fraternidade com o sistema capitalista, o qual privilegia o mercado, ao invés da ajuda mútua e da cooperação, dentre outros. (AMAYA, 2016).

Daí de se questionar se não será possível contar com a fraternidade no novo mundo que se anuncia pós-pandemia. É certo que o conceito de fraternidade é algo mais amplo do que a solidariedade, sendo esta uma de suas facetas, voltada ao auxílio aos necessitados e vulneráveis (AMAYA, 2016). Também há que se salientar que não se pode se contentar somente com esta, mas na atual conjectura político-econômica mundial, difícil visualizar a implementação de uma sociedade totalmente fraterna, porquanto tais relações subtendem uma igualdade por ora totalmente inexistente.

Portales diz que a fraternidade e a solidariedade podem caminhar juntas: "La idea de fraternidad evoca una serie de valores éticos y políticos como reciprocidad, cooperación, solidaridad, comunidad, familia" (PORTALES, 2016, p. 218), ao passo em que ambas também se opõem a valores em sintonia: "En oposición a la soledad, egoísmo, codicia, miseria, sufrimiento o el enemigo, en este aspecto, la fraternidad parece sinónimo de solidaridad”. (PORTALES, 2016, p. 218).

De fato, é por aí que podemos caminhar neste momento. A sociedade globalizada e capitalista como agora, não nos oferece mecanismos de implementação da fraternidade globalmente, contudo, permite que a solidariedade reine entre os povos, quiçá, caminhando cheia de esperança em busca da fraternidade global, que nos fará reconhecer um mundo só, um povo só, livres da desigualdade, irmãos na paz, no amor e na saúde. 


\section{Conclusão}

O presente texto teve como propósito principal tematizar a experiência ora vivenciada pela sociedade contemporânea trazida pela Covid-19, em diversos aspectos, do panorama sanitário, passando pelo social e econômico, indo até o político, à luz da fraternidade.

Traçou-se, por primeiro, um panorama geral das implicações do vírus na vida dos diversos segmentos sociais, sua forma de assimilação do contexto pandêmico, seus modos e opções de vivência ou sobrevivência no período, constatando-se que o atual sistema econômico capitalista e globalizado, não deu conta de conter a propagação do vírus, tampouco de cuidar dos cidadãos do mundo, de protegê-los e dar-lhes condições de passar com dignidade pelos tempos difíceis que todos somos obrigados a atravessar. Não é mesmo um paradoxo que países tão ricos deixem seus nacionais vivenciarem uma situação tão precária? Que tanta riqueza não dê conta de dar a dignidade mínima a seus cidadãos no enfrentamento de uma crise?

Questiona-se se os efeitos deixados pela pandemia na vida destes milhões de pessoas seriam os mesmos se o mundo optasse pelo ser, em detrimento do ter, pela preservação de vidas, da própria natureza que dá vida, ao invés da economia. Mais uma vez, tem-se a chance de repensar conceitos, modos de viver e prioridades, a história dá a oportunidade.

O homem constatou que não há um bem-estar individualizado, pois o seu estado repercurte no dos demais seres, e que não depende só de si para conquistá-lo, entendendo, ao final, que os bens materiais que tanto se valoriza no atual sistema capitalista, não são suficientes para nos trazer felicidade, nem o foram para conter a pandemia ou diminuir sua força, pois a quarentena traz consigo a consciência de que precisa-se de mais para viver a paz, de muito mais para se viver em paz, precisa-se do outro e que este outro esteja bem.

Considerando o momento atual, a esperança é arcabouço que precisa ser forte o bastante para sustentar, e clamar pela visibilidade da atual conjuntura, dos seus reflexos na vida da sua gente, do seu povo, do seu semelhante à luz da solidariedade, quiçá da fraternidade.

O paradoxo continua entre nós, mas faz-se mister conseguir enxergar que a fraternidade não terá seu espaço enquanto o capitalismo for a opção, pois não há como privilegiar pessoas ao invés da economia, porque está na sua raiz. A humanidade precisa caminhar, tem a oportunidade de avançar, o questionamento que fica é se terá forças para tal, para dizer não aos excessos, ao que não precisa, ao que não foi o bastante para lhe proteger durante este período em que o invisível bate à porta, e dizer sim, ao que dignifica o ser, à divisão, ao compartilhamento, a uma igualdade substancial e enfim, à fraternidade. 


\section{REFERÊNCIAS}

\section{ALERTA PARA RISCO DE AUMENTO DA VIOLÊNCIA DOMÉSTICA NA}

PANDEMIA. Senado Federal, 2020. Disponível em:

$<$ https://www12.senado.leg.br/noticias/materias/2020/05/05/observatorio-alerta-para-risco-deaumento-da-violencia-domestica-na-pandemia. Acesso em: 19 de jun. de 2020.

AMALIA, Amaya. La relevancia de la fraternidad. In: LEROUX, Sergio Ortiz (Coord.). Las formas de la fraternidad. Cidade do México: Instituto de Investigaciones Filosóficas, 2016.

BOFF, Leonardo. Saber cuidar: ética do humano, compaixão pela terra. Rio de Janeiro: ed. Vozes, 1999, passim.

BRANSWELL, Helen; JOSEPH, Andrew. Who declares the coronavirus outbreak a pandemic. Stat News. 11, de mar. de 2020. Disponível em:

https://www.statnews.com/2020/03/11/who-declares-the-coronavirus-outbreak-a-pandemic/. Acesso em: 15 de jun. de 2020.

CRESCEM DENÚNCIAS DE VIOLÊNCIA DOMÉSTICA DURANTE PANDEMIA. Câmara dos Deputados, 2020. Disponível em: https://www.camara.leg.br/noticias/661087crescem-denuncias-de-violencia-domestica-durante-pandemia. Acesso em: 19 de jun. de 2020.

FRANCISCO, Papa. Vida após a pandemia. Vaticano: Libreria Editrice Vaticana, 2020.

FREIRE, Paulo. Pedagogia da esperança: um reencontro com a pedagogia do oprimido. Rio de Janeiro: Paz e Terra, 1992.

FREIRE, Paulo. Pedagogia do oprimido. 17 ed. Rio de Janeiro: Paz e Terra, 1987.

JOHNS HOPKINS. Arcgis, 2020. Disponível em:

https://www.arcgis.com/apps/opsdashboard/index.html\#/bda7594740fd40299423467b48e9ecf 6. Acesso em: 15 de jun. de 2020 .

PORTALES, Rafael Enrique Aguilera Portales. La solidaridad: un valor más allá de la fraternidad. In: LEROUX, Sergio Ortiz (Coord.). Las formas de la fraternidad. Cidade do México: Instituto de Investigaciones Filosóficas, 2016, p. 218.

SANTOS, Boaventura de Sousa. A cruel pedagogia do vírus. Ed. Almedina, 2020. 